\title{
Development of Physical and Chemical Processes to Increase the Efficiency of Concentration of Vinasse's Solids
}

\author{
Pietro Sica ${ }^{1}$, Antonio Sampaio Baptista ${ }^{1}$, Keshav Das $^{2}$ and Jose Piotrovski ${ }^{3}$ \\ 1. Department of Food Sciences (LAN) of Escola Superior de Agricultura «Luiz de Queiroz» (ESALQ), University of Sao Paulo, \\ Piracicaba, Sao Paulo 13416398, Brazil \\ 2. Driftmier Engineering Center,. University of Georgia, Athens, Georgia 30602, USA \\ 3. Tractebel, Agronomica, Florianopolis, Santa Catarina 88025-255, Brazil
}

\begin{abstract}
Each year, ethanol production is increasing in Brazil, consequently, the generation of byproducts as well. Among these, the vinasse stands out. With polluting power a hundred times greater than domestic sewage and high concentration of minerals, vinasse is generated in large volumes. Because of these characteristics, it is widely used in fertirrigation. However, it is composed of about $97 \%$ water, inflating the cost of the transport from the plant to the field. For these reasons, removing water from the vinasse and the consequent concentration of solids is an alternative management and application of this by-product. This project aimed to analyze the efficiency of various physical and chemical processes in the removal of water from the vinasse.
\end{abstract}

Key words: Vinasse, byproduct treatment, physical and chemical treatments, sugarcane mill, sustainable development.

\section{Introduction}

In recent decades, global energy policy is increasingly focused on renewable energy sources, seeking to reduce negative impacts on the environment in pursuit of sustainable development. In this aspect, Brazil has been highlighted in the production of biofuels, because is the country with the highest production of ethanol from sugarcane in the world.

According to UNICA (Sugarcane Industry Union) [1], in the season 2015-2016, 590 million tons of sugarcane was processed in Brazil's center south region, producing about 30.3 billion liters of ethanol. In addition, the Ten Year PDE (Plan for Energy Expansion, 2022), from the MME (Ministry of Mines and Energy) [2], predicts that Brazilian Ethanol production could double by the year of 2022, reaching 57.3 billion liters.

Corresponding author: Pietro Sica, undergrad, main research field: environmental sciences.
The sugarcane industry is known for generating large amount of waste. In 2006, Jendiroba, E., et al. [3] said the industry developed by resizing the removal of waste in proportion to their generation, being impractical storage of such waste during the harvest. In this sense, Godoy, S. G. M. [4] points out that, if the waste is well managed, it will reduce production costs, improve the company's image and business prospects and mainly reduce the risk of environmental damage.

According to Rossetto, A. J. [5], vinasse, stillage or distillery syrup is resulted by the ethanol production. The amount of vinasse produced by the distillery is due to the alcohol percentage obtained from the fermentation, ranging from 10 to 18 liters of vinasse per liter of ethanol produced. Moreover, according to Szymanski, M. S. E., Balbinot, R. and Nagel, W. [6], the steady increase in the ethanol production in Brazil is causing the increase in the generation of this by-product. Thus, in the 2015/2016 season, it can be 
estimated that were generated between 275 billion and 495 billion liters of vinasse in the central-southern Brazil. And according to the perspectives of the MME [2], the generation of vinasse would reach a volume of between 573 billion and 1,031 billion liters in the year 2022.

The vinasse is considered the main by-product of the industry because besides the large amounts in which it is generated, its polluting power is about 100 times greater than the sewage. This can be explained by the high concentration of organic matter, low $\mathrm{pH}$, high corrosiveness, high levels of COD (Chemical Oxygen Demand) and BOD (Biological Oxygen Demand), in addition to high temperature at the exit of the distillation apparatus (approximately $80{ }^{\circ} \mathrm{C}$ ). Therefore, it is considered highly harmful to fauna, flora, micro fauna and microflora of fresh water [7]. Besides these characteristics, vinasse also has high concentrations of minerals such as calcium, sulfate and potassium, as can be seen in Table 1 .

Due to the high concentration of potassium ions $\left(\mathrm{K}^{+}\right)$, if applied to the soil, vinasse may cause changes in the dynamics of the ions. Potassium ions can form chemical complexes with other elements, such as nitrate anionswhich, if leachate can pollute groundwater [9]. This is the major concern arising from the use of vinasse, leaving environmental agencies alert to the way in which it is managed.

According to the Brazilian Ministry of Environment [10], the SAG (Guarani Aquifer System) is an underground and transboundary water body covering part of the territories of Argentina, Brazil, Paraguay and Uruguay. It has an accumulated volume of 37,000 $\mathrm{km}^{3}$ and estimated area of $1,087,000 \mathrm{~km}^{2}$. In the Brazilian part extends to eight states: Goiás, Mato Grosso, Mato Grosso do Sul, Minas Gerais, Paraná, Rio Grande do Sul, Santa Catarina e São Paulo.

In 1991, Hirata, R. C. A., et al. [11] showed that the region that concentrates much of the production of sugar and alcohol in the State of São Paulo (Fig. 1)
Table 1 Physico-chemical characteristics of the vinasse generated from the distillation of fermented mixture of sugarcane juicy and molasses (Adapted [8]).

\begin{tabular}{ll}
\hline Parameters & Mixedjuicy \\
\hline $\mathrm{pH}$ & $4.4-4.6$ \\
Temperature & $80-100$ \\
$\mathrm{COD}(\mathrm{mg} / \mathrm{L})$ & 45,000 \\
Total Solids $(\mathrm{mg} / \mathrm{L})$ & 52,700 \\
Nitrogen $(\mathrm{mg} / \mathrm{LN})$ & $480-710$ \\
Phosphor $\left(\mathrm{mg} / \mathrm{LP}_{2} \mathrm{O}_{5}\right)$ & $9-200$ \\
Potassium $\left(\mathrm{mg} / \mathrm{LK}_{2} \mathrm{O}\right)$ & $3,340-4,600$ \\
Calcium $(\mathrm{mg} / \mathrm{LCaO})$ & $1,330-4,570$ \\
Magnesium $(\mathrm{mg} / \mathrm{LMgO})$ & $580-700$ \\
Sulfate $\left.(\mathrm{mg} / \mathrm{LSO})_{4}\right)$ & $3,700-3,730$ \\
\hline
\end{tabular}

is located on the call charging region of SAG (Fig. 2). In this region, the groundwater is relatively close to the surface, which makes them vulnerable to infiltration of pollutants, especially potassium salts and nitrates, by leaching.

For these reasons, CETESB (Environmental Company of the State of São Paulo), through the Technical Standard P 4231, in 2006 [12], established a set of rules for the management and application of vinasse on the soil. Thus, the dosage of vinasse to be applied to agricultural land in sugarcane crop must be determined by the equation:

$$
\mathrm{V}=[(0.05 \mathrm{xCEC}-\mathrm{ks}) \times 3,744+185]: \mathrm{kvi}
$$

Where:

- $\mathrm{V}=\mathrm{m}^{3}$ of vinasse per hectare;

- $0.05=5 \%$ of CEC (Cation Exchange Capacity) of the soil;

- $\mathrm{CEC}=\mathrm{CEC}$ of the soil, expressed in $\mathrm{cmolc} / \mathrm{dm}^{3}$;

- $\mathrm{ks}=$ concentration of potassium in the soil to a depth of 0 to $80 \mathrm{~cm}$, expressed incmolc $/ \mathrm{dm}^{3}$;

- $3,744=$ constant to transform the amount of potassium from $\mathrm{cmolc} / \mathrm{dm}^{3}$ to $\mathrm{kg}$ of potassium in a volume of one (01) hectare per $0.80 \mathrm{~m}$ depth;

- 185 = weight, in $\mathrm{kg}$ of $\mathrm{K}_{2} \mathrm{O}$, extracted by culture, by harvest;

- $\mathrm{kvi}=$ potassium concentration in the vinasse, expressed in $\mathrm{K}_{2} \mathrm{O} / \mathrm{m}^{3}$.

Thus, the maximum volume of vinasse per hectare is based on the potassium concentration in the vinasse 


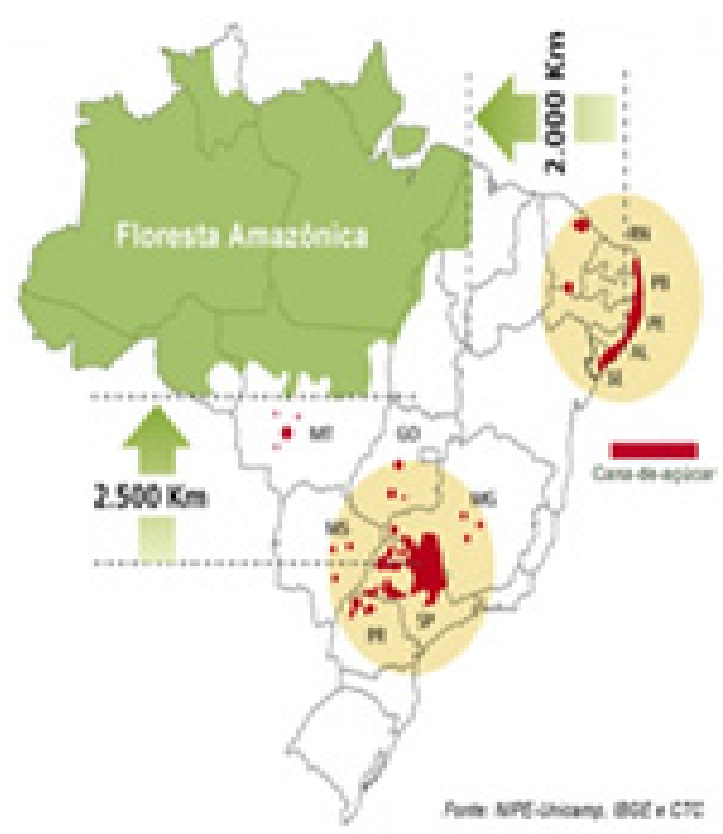

Fig. 1 Sugarcane area in Brazil.

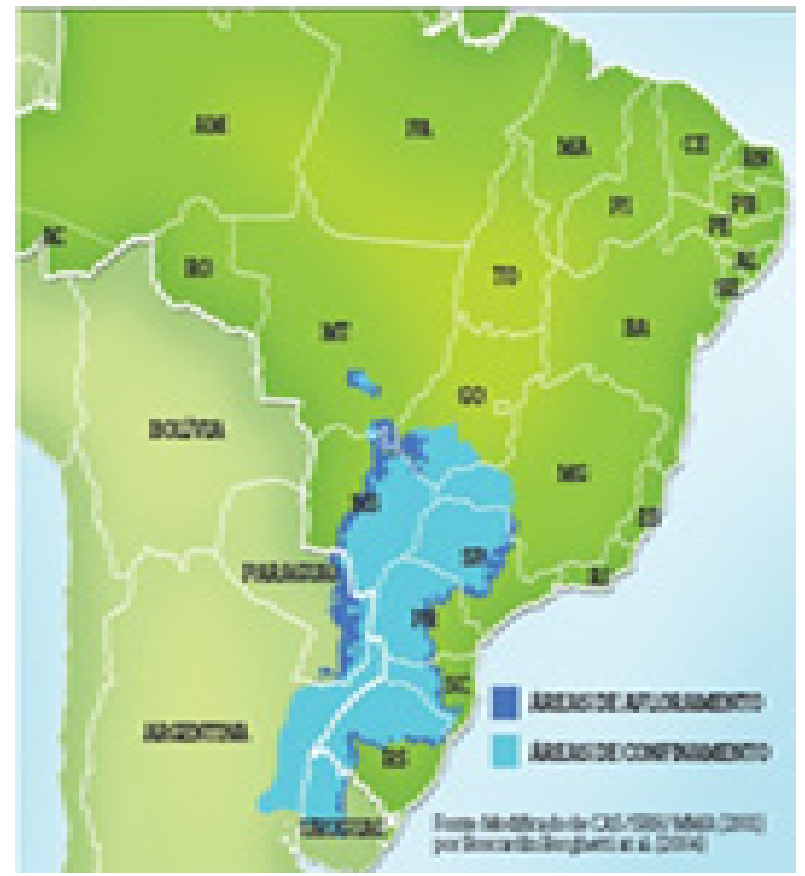

Fig. 2 Extension of SAG.

and the potassium concentration to a depth of 0 to 80 $\mathrm{cm}$ of the soil and it's CEC. That is, the maximum concentration of potassium can not exceed $5 \%$ of soil CEC and, if it occurs, will be restricted to the replacement of extraction of this nutrient on the average extraction of culture, which is $185 \mathrm{~kg} \mathrm{~K}_{2} \mathrm{O}$ per hectare per cut.
Due to the volume produced, low concentration of total solids (about 2\%) and the limits of application per unit area, imposed by CETESB, spending on transportation of this waste are very high. According to Rodella, A. A., et al. [9], the freight paid for the transport of vinasse to a distance of $20 \mathrm{~km}$ to $25 \mathrm{~km}$ is around 160.00 reais (or 40.00 dollars) per truck.

Seeking greater efficiency in the application of vinasse, combined with lower costs, especially reducing the environmental impact, the sugarcane industry has been investing in technology to reduce the volume of the waste generated, as fermentation with high alcohol content and the concentration of vinasse.

According to Faria, A. A. A., et al. [13], the concentration of vinasse can be a source of water (about $97 \%$ of its composition) for the sugarcane industry, in addition to reducing the volume of vinasse to be transported to the field, with an option to reduce transportation costs in tanker trucks to the field with fertilization purposes.

The physico-chemical treatment of wastewater is to associate chemical and physical processes, such as flocculation and sedimentation, respectively. The aim of this treatment is to remove or reduce particles in the liquid phase. Such as: suspended solids, bacteria, viruses, heavy metals, nutrients and other organic materials that are not in accordance with the intended use [14]

Despite having high concentrations of organic matter and nutrients such as potassium, the chemical composition of vinasse is mostly water (97\%) [15]. Of the various proposed methods of concentration, Nataraj, S. K., et al. [16] report a hybrid separation process of nanofiltration and reverse osmosis for the removal of color and contaminants of vinasse. The choice of the most appropriate treatment technique for physical-chemical treatment depends on several factors, such as physical and chemical characteristics of the effluent, treatment goal, the viability of economic, environmental and mainly, operational, 
Table 2 Some of the physical and chemical processes and their applications.

\begin{tabular}{|l|l|}
\hline Process: & Application: \\
\hline Coagulation & $\begin{array}{l}\text { Destabilization of particle matter, helping } \\
\text { aggregation and floc formation for } \\
\text { subsequente physical removal. }\end{array}$ \\
\hline Floculation & $\begin{array}{l}\text { Aggregation of small particles into larger } \\
\text { particles, helping the removal by } \\
\text { sedimentation or flotation. }\end{array}$ \\
\hline Centrifugation & $\begin{array}{l}\text { Separation of solid-liquid phases. } \\
\text { Dewatering and sludge concentration. }\end{array}$ \\
\hline Settling & $\begin{array}{l}\text { Removal of settleable solids and flocculated } \\
\text { particles. Sludge concentration. }\end{array}$ \\
\hline
\end{tabular}

Source: Adapted from Ref. [14].

since the large amount vinasse that is generated. Table 2 describes some of the key physical and chemical processes and their applications [14].

Therefore, the purpose of this project was to evaluate the efficiency of ferric sulfate, aluminum sulfate and tannic acid in different concentrations and settling timesin addition to testing the efficiency of filtration and centrifugation in the treatment of vinasse.

\section{Experimental}

The vinasse used was collected in a distillation plant of a sugarcane mill located in the state of São Paulo. Thereafter, it was concentrated with the aid of an evaporator and stored at $-5{ }^{\circ} \mathrm{C}$. Before the start of the experiments, vinasse was diluted with distilled water, returning to its original features [17].

At first, vinasse was centrifuged at $4.000 \mathrm{rpm}$ for 10 minutes aiming solid/liquid separation. The supernatant was submitted to the process of flocculation/coagulation, with the $\mathrm{pH}$ adjusted to 7.5 using lime milk, and subsequently adding aluminum sulfate in concentrations of $100 \mathrm{ppm}$ and $200 \mathrm{ppm}$. Settling occurred at room temperature and $70{ }^{\circ} \mathrm{C}$ for $12 \mathrm{~h}$, since the vinasse comes off at elevated temperatures of the distillation tower. Treatments were performed in 4 replicates and are presented in Table 3.

After the settling time, all treatments were siphoned, separating the supernatant of the settled solids. Then, the supernatant was filtered in sand filters (Fig. 4)
Table 3 Treatments of the experiment 3.

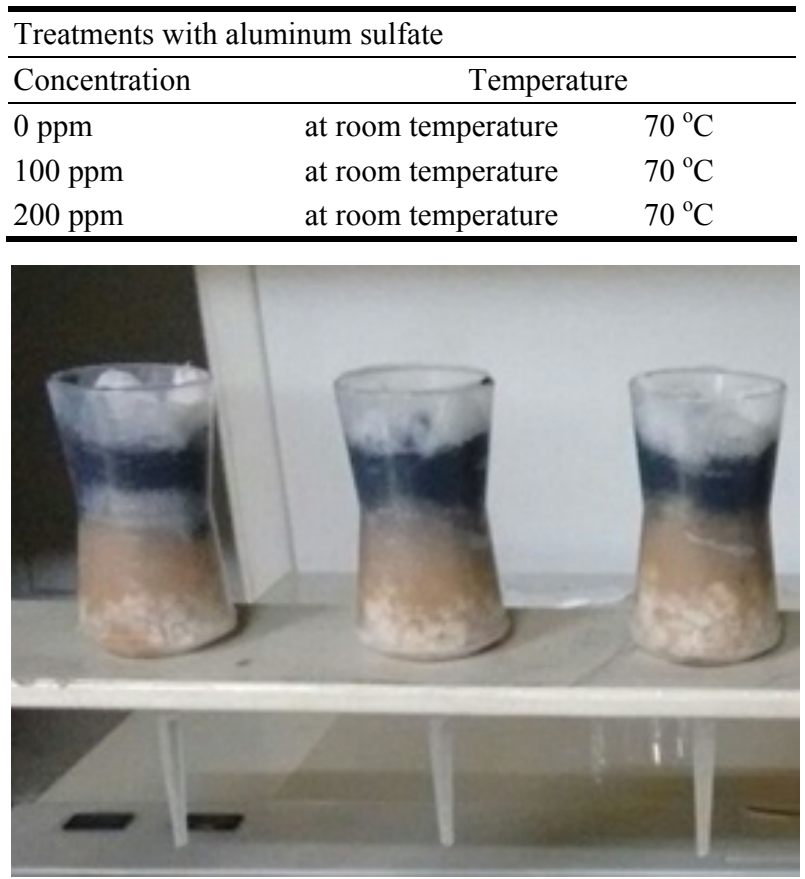

Fig. 3 Sand filters used on experiment 3.

Fig. 4 is a flow chart with the physical and chemical processes used in the experiment.

\subsection{Analysis}

\subsubsection{Turbidity}

Turbidity was measured using a Portable Turbidimeter, based on nephelometry by the Standard Method of APHA (American Public Health Association, 1995).

\subsubsection{Total Solids}

The amount of total solids in the vinasse, in the supernatant after sedimentation and centrifugation was performed gravimetrically, consisting in quantifying the amount of the crucible and the sample value before and after subjected to the $105^{\circ} \mathrm{C}$ oven for 24 hours. After this period, the sample is removed from the oven, cooled in a desiccator and weighed. The value is given in percent of total solids.

\subsection{3 $\mathrm{pH}$ and Conductivity}

The $\mathrm{pH}$ and conductivity were determined with the aid of a portable device Accumet ${ }^{\circledR A P} 62 \mathrm{pH} / \mathrm{mv}$ Meter-Fisher Scientific, USA. 


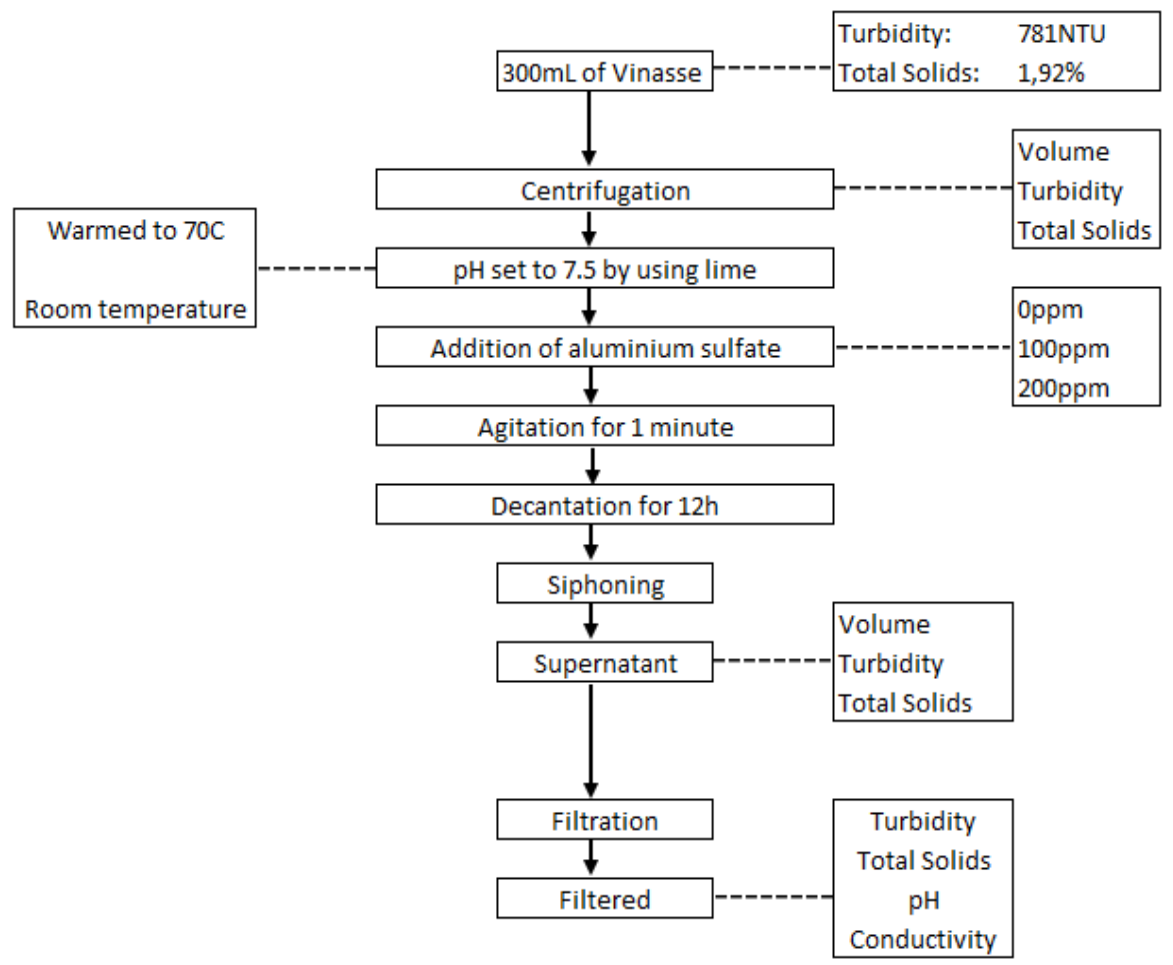

Fig. 4 Physical and chemical processes used in the experiment.

\section{Results and Discussion}

This experiment was carried out using aluminum sulfate. The $\mathrm{pH}$ was adjusted to 7.5 using milk of lime in the following treatments: (T1) $0 \mathrm{ppm}$, settling at room temperature; (T2) $0 \mathrm{ppm}$, settling at $70{ }^{\circ} \mathrm{C}$; (T3) $100 \mathrm{ppm}$ settling at room temperature; (T4) $100 \mathrm{ppm}$, settling at $70{ }^{\circ} \mathrm{C}$; (T5) $200 \mathrm{ppm}$ settling at room temperature; (T6) $200 \mathrm{ppm}$ settling at $70{ }^{\circ} \mathrm{C}$. After 12 hours of settling, the supernatant was syphoned and filtered through sand filters.

The vinasse used had initial turbidity of 781 NTU (Nephelometric Turbidity Unity), pH 4.33, conductivity +133 and $1.92 \%$ total solids. On the experiments 1 and 2, was possible to observe that the centrifugation process is more efficient than the settling process on turbidity reduction. Because of these, on the experiment 3 , it was centrifuged before the other processes, removing solids and lowering the turbidity of the supernatant at $74.01 \%$ (203 NTU). After being centrifuged, the $\mathrm{pH}$ was set to 7.5 , using lime milk. The reagent was added, mixed for 1 minute and left settling for 12 hours. After the settling time, the supernatant passed through a filtration process in a filter containing activated carbon, fine sand, coarse sand, small gravel stone, large crushed stone and gauze. The characteristics of the vinasse before and after centrifugation are on Table 4 .

Table 4 shows that centrifugation does not affect the $\mathrm{pH}$ and conductivity parameters. However, it reduced total solids of vinasse from $1.93 \%$ to $1.67 \%$, and $6.25 \%$ of the initial volume. Furthermore, the turbidity was reduced by $74.01 \%$, lowering from 781 NTU to 203 NTU. After this process, the $\mathrm{pH}$ was adjusted to 7.5 using lime milk, and aluminium sulfate was added and then left settling for 12 hours.

Table 4 Characteristics of vinasse before and after being centrifuged.

\begin{tabular}{lll}
\hline Vinasse: & Initial & Centrifuged \\
\hline TS & 1.93 & 1.67 \\
Volume (mL) & 400 & 375 \\
$\mathrm{pH}$ & 4.33 & 4.33 \\
Conductivity (mV) & +133 & +133 \\
Turbidity (NTU) & 781.00 & 203.00 \\
Turbidity reduction (\%) & 0.00 & 74.01 \\
\hline
\end{tabular}


After 12 hours settling, the supernatant was siphoned and total solids and turbidity reduction were analysed. In all treatments the turbidity increased, comparing with the centrifuged vinasse, before the addition of reagents. The turbidity increased more on the treatments at $70{ }^{\circ} \mathrm{C}$, as can be seen on Table 5. It happened because the high temperature evaporated a part of the water, increasing the turbidity in the supernatant. However, the total solids decreased in all treatments. The $100 \mathrm{ppm}$ and $200 \mathrm{ppm}$ at room temperature were the treatments which decreased more the total solids, from $1.67 \%$ to $1.53 \%$. Besides that, on the treatments which were added aluminium sulfate, the $\mathrm{pH}$ decreased.

Then, the supernatant was filtered in a sand filter. The filtration process was efficient on turbidity reduction, solids and color removal. As can be seen in Table 6 and Graph 1, after the filtration process, all the treatment had more than $90 \%$ of turbidity reduction. In this aspect, the treatments which were added 200 ppm of aluminium sulfate got the greatest results, reducing in $96.80 \%$ the turbidity, from 781 NTU to 25 NTU after all processes.

Table 5 Total solids, $\mathrm{pH}$, conductivity and turbidity of the supernatant after 12 hours settling.

\begin{tabular}{lllll}
\hline Treatments & TS $(\%)$ & $\mathrm{pH}$ & $\begin{array}{l}\text { Conduc. } \\
(\mathrm{mV})\end{array}$ & $\begin{array}{l}\text { Turbidity } \\
(\mathrm{NTU})\end{array}$ \\
\hline Centrifuged & 1.67 & 4.33 & 133 & 203 \\
T1 & 1.60 & 7.52 & -28 & 203 \\
T2 & 1.62 & 7.51 & -28 & 226 \\
T3 & 1.53 & 6.54 & 26 & 227 \\
T4 & 1.59 & 6.53 & 27 & 236 \\
T5 & 1.53 & 5.82 & 60 & 218 \\
T6 & 1.65 & 5.82 & 60 & 249 \\
\hline
\end{tabular}

Table 6 Total solids, $\mathrm{pH}$ and turbidity reduction of the filtered product.

\begin{tabular}{llll}
\hline Treatments & TS $(\%)$ & $\mathrm{pH}$ & Turbidity reduction $(\%)$ \\
\hline T1 & 0.43 & 6.40 & 95.93 \\
T2 & 0.42 & 6.93 & 94.49 \\
T3 & 0.35 & 7.10 & 93.85 \\
T4 & 0.59 & 6.53 & 90.65 \\
T5 & 0.15 & 7.04 & 96.80 \\
T6 & 0.35 & 6.91 & 96.80 \\
\hline
\end{tabular}

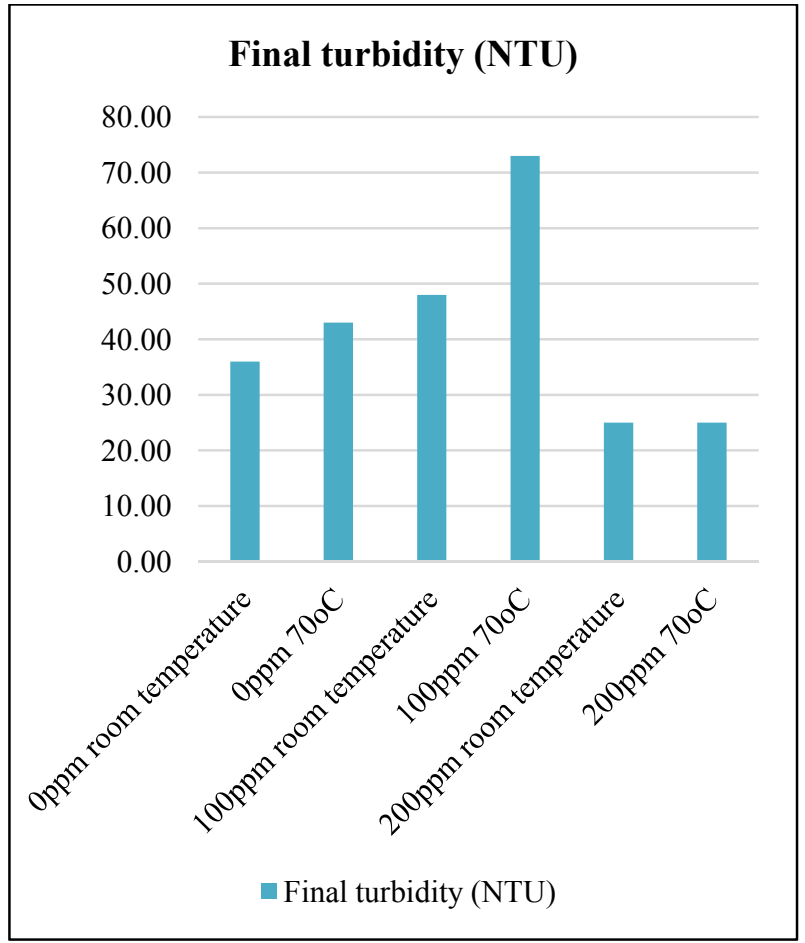

Graph 1 Final turbidity of the filtered product.

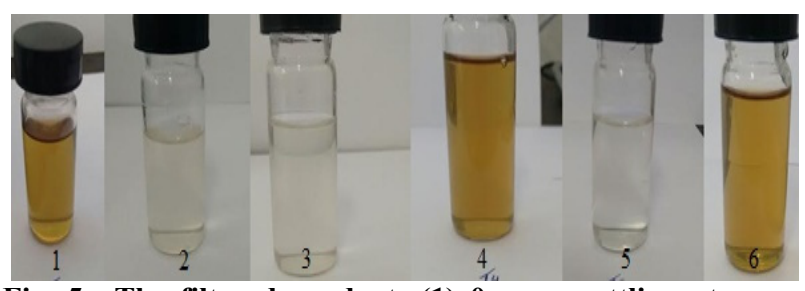

Fig. 5 The filtered product: (1) 0 ppm, settling at room temperature; (2) $0 \mathrm{ppm}$, settling at $70{ }^{\circ} \mathrm{C}$; (3) $100 \mathrm{ppm}$ settling at room temperature; (4) $100 \mathrm{ppm}$, settling at $70{ }^{\circ} \mathrm{C}$; (5) $200 \mathrm{ppm}$ settling at room temperature; (6) $200 \mathrm{ppm}$ settling at $70^{\circ} \mathrm{C}$.

Comparing the final total solids on the supernatant, is possible to observe on Table 6 that among all treatments, the treatment $200 \mathrm{ppm}$ at room temperature is the one that removed more solids after all processes, from $1.92 \%$ on the initial vinasse to $0.15 \%$ on the filtered product $(92.19 \%$ of solids were removed). While the other treatments obtained final total solids from $0.35 \%$ until $0.59 \%$ on the supernatant. That is, between 2.33 and 3.93 times more solids on the supernatant than the most efficient treatment.

Treatments 2 and 3 show more efficient in color removal, although they were less effective in removal of solids and turbidity reduction as compared with the 
treatments 1,4 and 6 . The treatment 6 obtained the best result on turbidity reduction and removed $81.77 \%$ of the solids after all processes. But, this treatment was not as effective in color removal. On the other hand, the treatment 5 obtained the best results in all parameters. It was the one which reduced more the turbidity (96.80\%) and removed solids (92.19\%). Besides that, the treatment 5 got a clear look after filtered and its $\mathrm{pH}$ was 7.04 , the closest to 7.00 when authors compare all treatments.

\section{Conclusion}

This work focused on evaluating the efficiency of various physical and chemical methods in solid concentration of the vinasse, such as coagulation, flocculation, centrifugation, settling and filtration.

In all treatments with added reagents obtained more satisfactory final result of those treatments without reagent. Therefore, authors conclude aluminum sulfate help to make the vinasse treatment process more efficient.

In relation to physical processes, the centrifugation and filtration processes were very effective in reducing turbidity. However, centrifugation did not obtain results as satisfactory as the other two processes in removing solids.

It is worth highlighting the high efficiency of sand filter after the centrifugation, flocculation, coagulation and settling. After this process, it was possible to verify high solids removal and reduction of turbidity, besides obtained a transparent product, in some of the treatments.

However, the sugar cane industry is known for large-scale which makes products and by-products. So, more studiesare needed to verify the feasibility of implanting new processes at the plant.

Thus, this work played a significant role in the formation of a solid base of results and possible prospects. It will be possible to develop new experiments in larger scales, which will generate data closer to the reality of the sugarcane mill.

\section{References}

[1] Barros, S. 2016. Brazil Biofuels Annual Report. USDA (United States Department of Agriculture), Annual Report, 11.

[2] Brazilian Ministry of Mines and Energy (MME). 2013. “Ten Year Plan of Energy Expansion-Brazil." Accessed February 22, 2016. http://www.epe.gov.br/PDEE/ relatorio\%20Final $\% 20 \mathrm{do} \% 20 \mathrm{PDE} \% 2022$.pdf.

[3] Jendiroba, E., Segato, S. V., Pinto, A. S., Jendiroba, E., and Nobrega, J. C. N. 2006. "Environmental Issues in the Management of Sugarcane Agroindustry." Piracicaba: CP 2: 375-86.

[4] Godoy, S. G. M. 2005. "The Kyoto Protocol and the Clean Development Mechanism: Na Assessment of its Possibilities and Limits. 2015." Master Dissertation. Sao Paulo: PUC-SP.

[5] Rossetto, A. J. 1987. "Agronomic Use of By-products and Waste from the Sugar and Alcohol Industry." Campinas: Fundação Cargill 2: 435-504.

[6] Szymanski, M. S. E., Balbinot, R., and Nagel, W. 2010. "Anaerobic Digestion of Vinasse: Energy Use of Biogas and Carbono Credits-Case Report." Londrina: Workshop "Ciencias Agrarias" 31 (4): 901-12.

[7] Freire, W. J., and Cortez, L. A. B. 2000. "Use of Vinasse and Impacts on Soil and Ground Water Properties." Accessed February 22, 2016. http://www.scielo.br/pdf/rbeaa/v11n1/v11n1a14.pdf.

[8] Marques, M. O., Segato, S., Pinto, A., Jendiroba, E., and Nobrega, J. 2006. "Technical and Legal Aspects of the Production, Transport and Application of Vinasse." Update on Production of Sugarcane. Piracicaba: CP 2: 369-75.

[9] Rodella, A. A., Zambello Jr, E., and Francisco, J. O. 1986 "Effects of Vinasse Added to Soil on $\mathrm{PH}$ and Exchangeable Aluminium Content." 18 Congress of International Society of Sugar Cane Technologists, Ciudad de La Habana (Cuba), 21-26 Feb 1983. J. Marti Publishing House.

[10] Villar, P. C., and Ribeiro, W. C. 2014. "13. The Agreement on the Guarani Aquifer: Cooperation without Conflict." Global Water: Issues and Insight: 69.

[11] Hirata, R. C. A., Bastos, C. R. A., Rocha, G. A., Gomes, D. C., and Iritani, M. A. 1991. "Groundwater Pollution Risk and Vulnerability Map of the State of São Paulo, Brazil.” Water Science and Technology 24 (11): 159-69.

[12] Companhia, D. T. E. S. A. 2006. "Technical Standard P4. 231: Vinasse-Criteria and Procedures for Agricultural Soil Application." State of Sao Paulo.

[13] Faria, A. A. A., Duda, R. M., and de Oliverira, R. A. 2013. "Concentration of Vinasse and Water Reuse." Ciencia \& Tecnologia 3 (Supl) (in French). 


\section{Concentration of Vinasse's Solids}

[14] Metcalf \& Eddy, Burton, F. L., Stensel, H. D., and Tchobanoglous, G. 2003. Wastewater Engineering: Treatment, Disposal and Reuse. New York: McGraw Hill.

[15] Silva, L. C. F., Zambello Jr, E., Orlando Filho, J., and Arruda Filho, H. C. 2005. "Use of Dry Vinasse and Boiler
Ash as Fertilizer in Sugarcane Cultivation." Sao Paulo: STAB 1:.35-41.

[16] Nataraj, S. K., Hosamani, K. M., and Aminabhavi, T. M. 2006. "Distillery Wastewater Treatment by the Membrane-based Nanofiltration and Reverse Osmosis Processes." Water Research 40 (12): 2349-56. 